\title{
ARQUITETURA SOCIOLÓGICA
}

\author{
FREDERICO DE HOLANDA
}

R E S U M O A arquitetura é mais comumente considerada como oficio, arte ou técnica. O texto a considera também como ciência que aborda os lugares sob um olhar específico, não afeito a outras disciplinas. Examinam-se modalidades de conhecimento e sugere-se que houve uma mudança paradigmática no campo, nas últimas décadas. A mudança resgata o pensamento teórico-reflexivo. O fortalecimento da arquitetura como disciplina científica não anula; pelo contrário, fortalece a interdisciplinaridade no trato das questôes relativas aos lugares produzidos ou usufruidos pelas pessoas: enfatizam-se contribuiçôes de autores oriundos de outros campos disciplinares, que olham os lugares do ponto de vista morfológico. Explora-se a arquitetura como variável independente: uma vez pronta, afeta as pessoas em vários aspectos, entre eles os sociológicos, resumiveis nas seguintes perguntas: a configuração da forma-espaço (vazios, cheios e suas relaçôes) implica maneiras desejáveis de individuos e grupos (classes sociais, gênero, geraçōes etc.) localizarem-se nos lugares e de moverem-se por eles, e conseqüentemente condiçôes desejadas para encontros e esquivanças interpessoais e para visibilidade do outro? O tipo, quantidade e localização relativa das atividades implicam desejáveis padrôes de utilização dos lugares, no espaço e no tempo?

P A L A V R A S - C H A V E Relaçôes arquiteturalsociedade, arquitetura como ciência humana, arquitetura sociológica.

\section{INTRODUÇÃO}

A origem do texto remonta a discussões ocorridas no Encontro Nacional da ANPUR em Salvador, em maio de 2005. Por ocasião da Sessão Coordenada "Territorialidades e espaços urbanos e regionais: 'novas' abordagens teóricas", ressurgiu o tema arquitetura como disciplina. ${ }^{1} \mathrm{O}$ debate prolongou-se apaixonada e gostosamente em cafés da manhã e nos corredores do congresso. Na essência estavam as questóes: a arquitetura tem o direito de reivindicar um lugar no panteão das disciplinas científicas? Como caracterizar as relações com (ou a inserção entre) as ciências humanas, as ciências da natureza, as técnicas, as artes? A obviamente necessária interdisciplinaridade no trato do espaço urbano dispensa o desenvolvimento de um campo de reflexão específico - o da arquitetura da cidade - com teorias, métodos e técnicas que lhe são próprios? Esse campo não será amplo, a refletir as múltiplas dimensões da realidade arquitetônica? É possível enxergar na literatura publicada no Brasil e alhures indícios de que a construção de uma nova ciência encontra-se em marcha?

Ninguém na referida sessão defendeu o status de ciência para a arquitetura. MonteMór prefere investir na construção de um "campo multi-inter-trans-disciplinar" ${ }^{2}$ para conhecer "a cidade" onde importa pouco a especificidade de quaisquer enfoques. Villaça nega o status de ciência à arquitetura, que caberia à Geografia no trato do espaço urbano. Contradigo ambas as posiçōes ao identificar nelas visões epistemológicas que implicam bloqueio do avanço do conhecimento sobre importantes aspectos da realidade. Conhecer melhor os lugares de nossa vida cotidiana envolve o desenvolvimento de teorias, métodos

1 A Sessão foi coordenada por Geraldo Magela Costa e participaram Brasilmar Ferreira Nunes, Flávio Villaça, Roberto Luis de Melo Monte-Mór e Bertha K. Becker. 0 autor participou da platéia.

2 A expressão é minha, não de Monte-Mór, mas parece-me refletir o cerne de sua argumentação. Desculpo-me por quaisquer equívocos de interpretação sobre as idéias dos colegas, por quem nutro admiração e afeto. 
3 Assim o faz a maior parte da literatura, explicar a arquitetura por suas "determinações". Freqüentemente explica-se erradamente a arquitetura por suas determinacões econômicas, particularmente na tradição soi dizant marxista (para contestação de interpretações sobre Brasília, por exemplo, ver Holanda, 2002). Outra versão busca entender o projeto por suas "intencões" reveladas ou ocultas, palavra onipresente no discurso arquitetônico. Quando as intenções são explicitadas pelo arquiteto, não esquecamos de que se trata apenas de um discurso que pode refletir a realidade, mas pode encobrir, no mínimo por desconhecimento, no máximo por má fé, as reais implicações da arquitetura proposta. Pode ser simples "ideologia", no mau sentido - aparência a encobrir a essência das coisas. Os erros não invalidam a vertente.

4 Aqui encaixam-se os pesquisas de "avaliação pós-ocupação", e.g., Ornstein, 1997.

5 Gratidão a Sandra Soares de Mello por argutas considerações sobre versão preliminar das idéias.

6 Não se trata do "nós majestático". Refiro-me a idéias concebidas coletivamente no âmbito do grupo de pesquisa que coordeno, Dimensões morfológicas do processo de urbanização, registrado no Diretório de Grupos de Pesquisa no Brasil, CNPq.

7 As idéias foram publicadas por primeira vez em Holanda \& Kohlsdorf, 1995. Posteriormente venho "calibrando" 0 conceito. A versão aqui apresentada é inédita e de minha individual responsabilidade.

8 "A mais tolhida das artes, a arquitetura é, antes de mais nada, construção, mas construcão concebida com o propósito de organizar e ordenar plasticamente o espaço e os volumes decorrentes, em função de uma determinada época, de um determinado meio, de uma determinada técnica, de um determinado programa e de uma determinada intenção" (Costa, 1980). É evidente que Lucio Costa refere-se a intenções estéticas, implicando "boa qualidade estética". Abraçamos contudo a idéia de que todos edifícios têm um desempenho e técnicas que não estão contemplados pela Geografia, por quaisquer outras ciências humanas ou da natureza, menos ainda pela "interdisciplinaridade".

Abordo a seguir os temas: delimitação do conteúdo do texto; problemas de realidade e representação em arquitetura; aspectos que caracterizam o olhar arquitetônico sobre os lugares; constituição de uma disciplina da arquitetura e as subdivisóes; arquitetura como ciência humana e arquitetura sociológica; exemplos de análises empíricas que ilustram o argumento.

\section{DUAS BIFURCAÇÕES, DUAS ESCOLHAS}

$\mathrm{Na}$ teorização da arquitetura, identifico duas bifurcações iniciais, sobre as quais faço duas escolhas para delimitar o ensaio.

A arquitetura é variável dependente e variável independente, concomitantemente. Como variável dependente, a arquitetura é determinada pelo ambiente socionatural em que se realiza, por exemplo: clima, relevo, geologia, hidrografia, disponibilidade de materiais (ambiente natural); conhecimento científico-tecnológico, interesses econômico-políticoideológicos (ambiente social). Ela resulta disto. ${ }^{3}$ Por outro lado, como variável independente, a arquitetura tem efeitos. Enquanto artefato, ela impacta nossas vidas e o meio ambiente natural: ela determina se: 1) atividades têm suporte adequado para seu funcionamento; 2) condiçôes hidro-térmicas são confortáveis; 3) custos energéticos para manutenção são elevados; 4) há sensação de beleza etc. Ela resulta nisto. ${ }^{4}$ (Veremos que a arquitetura não é apenas artefatual.)

A primeira bifurcação é entre: 1) arquitetura como variável dependente e 2) arquitetura como variável independente. A escolha: examinarei a arquitetura como variável independente. E a segunda bifurcação: como variável independente, a arquitetura pode impactar: 1) o meio ambiente natural e 2) as pessoas. A escolha: examinarei o impacto sobre as pessoas. ${ }^{5}$

\section{ARQUITETURA: REALIDADE E CONCEITO}

Como em quaisquer âmbitos da realidade, empiricamente "arquitetura" não é um "dado", não existe em si, independentemente de nossas representações. Não se trata do subjetivismo obscurantista pós-moderno: não nego a realidade em si, mas aceito que qualquer análise de tão ampla generalidade - a "realidade" - pressupõe conceitos, reflexóes, representações. Assim, não há um "fato" arquitetura: ela consiste naquilo que é circunscrito por uma definição, por um ponto de vista que seleciona, inclui, exclui, qualifica; ela é "teoria-dependente".

Adotamos ${ }^{6}$ um conceito de arquitetura que evita reduções encontradas na literatura. ${ }^{7}$ Por exemplo, as formulações de Lucio Costa, ${ }^{8}$ Bill Hillier ${ }^{9}$ ou Evaldo Coutinho ${ }^{10}$ implicam inclusão de certas manifestações na "família arquitetônica" e exclusão de outras. Nossa definição alarga o âmbito em quatro direções: 1) todos os edifícios são arquitetura, não apenas os que revelam certa "intenção" (contradizendo Lucio Costa); 2) o espaço produzido por meio de um saber implícito, inconsciente, popular, é tão legitimamente arquitetura quanto o produzido pelo saber explícito e reflexivo (contradizendo Bill Hillier); 3) o espaço externo de ruas e praças é arquitetura, não apenas o espaço interno das edifi- 
cações (contradizendo Evaldo Coutinho); 4) finalmente, a paisagem virgem, natural, intocada pelo homem, tem uma configuração formal-espacial (adiante conceituada) passível de análise e avaliação enquanto arquitetura, tanto quanto o espaço artefatual de edifícios e cidades (contradizendo a vasta literatura onde "arquitetura" é considerada apenas como lugar construído pelo homem).

O conceito "configuração formal-espacial" inspira-se em Evaldo Coutinho: a arquitetura tem "componentes-meio" (os elementos "escultóricos", os "cheios", os "sólidos" a "forma") e "componentes-fim" (os "vãos", os "vazios", os "ocos", os "espaços") (Coutinho, 1970). Curiosamente, a teoria e a história da arquitetura têm se detido mais nos "componentes-meio": a volumetria, a composição das fachadas, texturas, cores, materiais etc. Todavia, estes pertencem especificamente à linguagem da escultura. Os elementos por excelência da linguagem arquitetônica são os "componentes-fim", os espaços - cômodos no edifício; ruas, avenidas, praças, parques, na cidade; lugares abertos na paisagem natural (Zevi, 1951, Hillier \& Hanson, 1984). Afinal, é neles que estamos imersos! Caracterizam-se por localização relativa ante outros espaços a implicar certas topologias, permeabilidade ou fechamento, transparência ou opacidade, valores de luz e sombra, ruídos, temperatura, movimentos do ar, aromas. "Meios" ou "fins", não podemos ignorar que somos afetados por uns e outros ao nos apropriarmos dos lugares. Há que teorizar, portanto, sobre "configuração formal-espacial" - ordenação conjunta dos dois tipos de componentes, todavia separáveis analiticamente.

Por nosso conceito, paisagem natural ou qualquer espaço construído são "arquitetura”. Mas ambos são apenas isto? Não. Uma montanha ou um edifício são fatos. Mas para além desta constatação banal, podem "ser" muitas coisas, a depender de como lançamos sobre eles nosso olhar reflexivo: por exemplo, para economistas, o edifício é "capital fixo"; para geólogos, a montanha é uma cristalização de movimentos da crosta terrestre; enquanto tais, edifício e montanha, como aqui caracterizados por economistas ou geólogos, não são arquitetura. Cabe à teoria mostrar como eles serão compreendidos enquanto arquitetura.

$\mathrm{O}$ desafio é identificar os aspectos que caracterizam a arquitetura. É isso que faz nossa proposição. Os "aspectos" são o artifício teórico para fundamentar a definição de arquitetura; resumem as implicações dos lugares enquanto arquitetura, como ela nos afeta de várias maneiras, o seu desempenho multifacetado. Os lugares têm outras implicações para as pessoas (como nos exemplos do "edifício" e da "montanha"). Mas as da taxonomia proposta são aquelas cuja investigação alimenta um corpo de conhecimento específico - o da disciplina arquitetura. A taxonomia a seguir explica-se sob forma de perguntas relativas a cada aspecto.

Aspectos funcionais. O lugar satisfaz as exigências práticas da vida cotidiana em termos de tipo e quantidade de espaços para as atividades, e seu inter-relacionamento?

Aspectos bio-climáticos. O lugar implica condições adequadas de iluminação, acústica, temperatura, umidade, velocidade do vento e qualidade do ar?

Aspectos econômicos. Os custos de implementação, manutenção e uso dos lugares são compatíveis com o poder aquisitivo das pessoas implicadas?

Aspectos sociológicos. A configuração da forma-espaço (vazios, cheios e suas relações) implica maneiras desejáveis de indivíduos e grupos (classes sociais, gênero, gerações etc.) localizarem-se nos lugares e de se moverem por eles e, conseqüentemente, condiçôes desejadas para encontros e esquivanças interpessoais, assim como para visibilidade do outro? O tipo, quantidade e localização relativa das atividades implicam desejáveis padrões de utilização dos lugares, no espaço e no tempo? estético - se bom ou mau são outros quinhentos; o mau desempenho não deve eliminar 0 edifício da "família". Com isso as razões do mau desempenho ficam de fora da reflexão disciplinar necessária.

9 "A arquitetura começa quando os aspectos configuracionais da forma e do espaço, pelos quais os edifícios se transformam em objetos culturais e sociais, são tratados não como regras inconscientes a serem seguidas, mas são elevados ao nível do pensamento consciente, comparativo, tornando-se desta maneira objeto de atenção criativa" (Hillier, 1996). A citacão é tomada do Capítulo 1 do livro, o qual tem por título, precisamente na linha de Lucio Costa, "O que a arquitetura acrescenta à construção". Hillier desloca o foco da realidade empirica da arquitetura para o seu processo de feitura. Sua redução convence ainda menos porque a ênfase não é estética, mas sociológica, foco dominante da teoria da sintaxe espacial. As pesquisas têm demonstrado que, em "aspectos sociológicos" fundamentais (ver abaixo), pouco difere a arquitetura anônima da "erudita".

10 Evaldo Coutinho está preocupado com a arquitetura enquanto veiculadora de uma visão de mundo. Para ele apenas o espaço interno constitui a arquitetura porque aqui todos os atributos espaciais são controlados para comunicar uma filosofia - 0 que ocorre bem menos no espaço aberto que, por tal, não tem controlados, da mesma maneira, luz, som, temperatura, aromas. (Coutinho, 1970) 
Aspectos topoceptivos (neologismo criado por Kohlsdorf, 1996). O lugar é legivel visualmente, isto é, ele tem uma identidade? O lugar oferece boas condições para a orientabilidade?

Aspectos afetivos. O lugar tem uma personalidade afetiva? Como ele afeta o estado emocional das pessoas - e.g. relacionado a solenidade, grandeza, frieza, formalidade, intimidade, informalidade, simplicidade etc.?

Aspectos simbólicos. O lugar é rico em elementos arquitetônicos que remetam a outros elementos, maiores que o lugar, ou a elementos de natureza diversa - valores, idéias, história?

Aspectos estéticos. O lugar é belo, isto é, há características de um todo estruturado e qualidades de simplicidade/complexidade, igualdade/dominância, similaridade/diferença, que remetem a qualidades de clareza e originalidade, e por sua vez a pregnância, implicando uma estimulação autônoma dos sentidos para além de questôes práticas? O lugar é uma obra de arte, por veicular uma visão de mundo? Sua forma-espaço implica uma filosofia?

Cada aspecto implica uma estrutura de relaçôes - um código - entre dois tipos de elementos: 1) atributos da forma-espaço; 2) expectativas humanas (Hillier \& Leaman, 1974). Códigos bio-climáticos relacionam tamanho, forma e disposição de aberturas para o vento (um lado) e sensações térmicas (outro lado); códigos topoceptivos relacionam forma e disposição de marcos visuais na cidade (um lado) e condiçôes para a orientabilidade (outro lado); etc. A tarefa da teoria é estabelecer as categorias analíticas relativas às duas famílias de elementos. Mais: a cada aspecto corresponderá certo número de categorias analíticas, no âmbito da arquitetura e no âmbito das expectativas sociais. Por exemplo, descrever bio-climaticamente a arquitetura não é descrevê-la esteticamente. A taxonomia apresentada acima encontra-se continuamente em teste nos nossos trabalhos de pesquisa. O desafio é aperfeiçoar as categorias analíticas: minimizar redundâncias entre as que pertencem a aspectos diferentes (se elas são as mesmas, não se justifica a autonomia taxonômica dos aspectos), descobrir novas categorias, descartar as que se mostram pouco explicativas.

Códigos arquitetônicos são de amplitude diversa, a depender do aspecto: 1) há os universais - e.g. exigências quanto às características visuais dos lugares, de modo que os gravemos facilmente em nossa mente, e são idênticas para todos os seres humanos, dado nosso aparelho perceptivo comum; 2) há os grupais - e.g. a configuração dos lugares impacta expectativas sociológicas que são historicamente determinadas, no tempo e no espaço; cada classe social têm seu código; 3) há os individuais: lugares impactam esteticamente a gente em função de valores que podem ser pessoais e intransferíveis - a empatia que sinto por um exemplo arquitetônico é função da similitude entre minha visão de mundo e a subjacente ao lugar, contida na configuração formal-espacial.

Dado o exposto, segue-se uma definição de arquitetura enquanto realidade captada por um olhar:arquitetura é lugar usufruido como meio de satisfação de expectativas funcionais, bio-climáticas, econômicas, sociológicas, topoceptivas, afetivas, simbólicas e estéticas, em função de valores que podem ser universais, grupais ou individuais.

11 Personagem de Eça de Queirós em 0 primo Basílio, apegado a frases feitas, ao discurso do óbvio.

\section{A DISCIPLINA DA ARQUITETURA, AS SUBDISCIPLINAS, A INTERDISCIPLINARIDADE}

O Conselheiro Acácio ${ }^{11}$ poderia ter dito: "tudo é complexo". E acrescentado: "a arquitetura não escapa". Com os aspectos, tentamos ultrapassar a obviedade e revelar o 
oculto: discriminar, separar, classificar, analisar, fazer jus à natureza multifacetada da arquitetura, explicitada na decomposição apresentada. Decorre que são muitos os "saberes" relacionados à prática e à teoria arquitetônicas. Eles variam quanto às maneiras de sua produção e aplicação (modos de pensar e agir) e quanto aos tipos de agentes envolvidos: alguns saberes são de domínio específico dos arquitetos, outros pressupõem interfaces com outros profissionais ou pesquisadores. Na evolução recente do pensar e fazer arquitetura, e nas relações com outras áreas, podemos identificar quatro "modos", que se desenvolvem de maneira aproximadamente cronológica. O Quadro 1 será utilizado como guia da discussão.

\section{MODO 1: SAVOIR FAIRE ARQUITETÔNICO: PRÁTICO E IMPLÍCITO}

A cada aspecto da arquitetura corresponde um campo de saber que se encontra: 1) em parte implícito, inconsciente, utilizado intuitivamente, prático porque colado à experiência; 2) em parte explícito, sistemático, reflexivo, teórico porque abstrai da experiência características estruturais, generalizáveis e aplicáveis a outras situações. No primeiro caso (Quadro 1, campo "1"), estamos no âmbito do savoir faire do "mestre de ofícios", que absorve na prática os saberes arquitetônicos, por imitação dos mestres ou por observação empírica do mundo, e os utiliza nos projetos. Honrosas exceções à parte, o campo "1" representa a pouca importância tradicionalmente dada aos aspectos teórico-analíticos na formação dos arquitetos: a arquitetura é mais entendida como "arte" ou "técnica" onde se aplicam conhecimentos produzidos alhures, não como, ela mesma, campo de produção de conhecimento. Contudo, seria errado "demonizar" a formação "irreflexiva" dos mestres de ofício intuitivos, os "arquitetos de prancheta", como pejorativa e injustamente às vezes são referidos na academia. Não são necessariamente maus arquitetos. Se assim o fosse, a arquitetura não teria avançado antes do advento histórico do modo científico de pensar. Arquitetos intuitivos podem ser providos de poderosas "antenas" que os facultam apreender (mesmo inconscientemente) a realidade, identificar problemas e propor inventivas soluções. Entretanto, outros modos de pensar e agir sobre os lugares abrem outras possibilidades.

Quadro 1 - Modos de fazer e pensar a arquitetura - décadas recentes

\begin{tabular}{ccc}
\hline 1 & 2 & 3 \\
savoir faire & pensamento & Ciências \\
arquitetônico: & morfológico: & reflexivo e \\
prático e & analítico & sociais e naturais: \\
implícito & Conhecimento \\
& & a-espacial \\
\hline
\end{tabular}

\section{MODO 2: REFÚGIO NO MUNDO A-ESPACIAL}

A identificação dos problemas do urbanismo moderno a partir dos anos 1950 levou a uma mudança comportamental dos arquitetos ante o conhecimento: a "febre inter-disciplinar" dos anos 1960-70. Identificamos que havia algo de insatisfatório com o saber arquitetônico da época, mas em vez de aprofundarmos reflexivamente o conhecimento da configuração dos lugares, investindo no campo "2", passamos direto para o campo "3", buscando, particularmente nas ciências sociais, a luz que revelaria nossas limitaçôes. Elas 
12 Professores ou alunos de arquitetura nos anos 1970 sabemos dos danos que isto causou à formação. Valia de tudo nos trabalhos de conclusão de curso, até despachos de macumba, como pude testemunhar (nada contra os despachos, mas estavam fora de contexto). Ver também comentários em Zein, 2001.

13 Mais adequado seria dizer que a ruptura dos anos 1960 70 marca o começo do fim de um "paradigma" e o início de outro. 0 progresso do conhecimento dá-se de maneira descontínua - são as "revoluções paradigmáticas" de Kuhn (2003). Na teoria da arquitetura, as últimas décadas testemunham uma destas revoluções.

14 Há estudo sobre os aspectos realizado com estudantes de arquitetura, na FAU-UnB (Holanda, s.n.). não puderam ajudar, não por culpa sua, mas por erro nosso. Levou tempo para descobrirmos (alguns pesquisadores infelizmente ainda não o fizeram) que as disciplinas consolidadas (campo "3") têm métodos próprios, categorias analíticas específicas, um vasto corpus de conhecimento que não dominamos, e que, principalmente, partem de descrições sistemáticas e rigorosas de outras realidades, circunscritas pelos respectivos campos conceituais - não da realidade dos lugares olhados como arquitetura. Lançam outros olhares sobre o mundo, mesmo quando o fazem sobre os mesmos objetos empíricos (novamente servem os exemplos do "edifício" e da "montanha"). Não têm um olhar morfológico: não dissecam a forma-espaço dos lugares para compreender seu impacto em nossas vidas. Por isso, o pulo do campo " 1 " para o " 3 " não teve impacto em projeto: continuamos a cometer os mesmos erros. Pior: o comportamento implicou o abandono do campo arquitetônico, fazendo com que trabalhos de "projeto" dentro das escolas de arquitetura se resumissem a documentos "sociológicos" ou "econômicos" - que não eram uma coisa nem outra - ou outros produtos de variada natureza. ${ }^{12}$ A relação com as disciplinas do campo "3" é fundamental para o avanço do conhecimento em arquitetura, mas de outros modos.

\section{MOdO 3: ARQUITETOS INTUITIVOS... E REFLEXIVO-ANALÍTICOS}

Não se tratava, portanto, de abandonar a arquitetura, passando do campo "1" para o "3", mas de aprofundar o conhecimento morfológico: adicionar à intuição, ao saber prático e implícito, um outro, construído a partir da observação sistemática da realidade, à qual aplica-se uma reflexão teórica que extrai dos lugares atributos estruturais; somar ao campo "1" os conteúdos do campo "2", o campo do saber objetivo (Popper, 1963) - reflexivo, verificável, refutável, contínua e racionalmente enriquecido. Não é uma novidade, mas a retomada de uma rica tradição - que o diga a antologia de Kruft (1994). Seria incorreto e arrogante dizer que estaríamos somente agora inventando o saber objetivo em arquitetura. $^{13}$

A retomada do conhecimento reflexivo em arquitetura tem contribuído para a consolidação de subdisciplinas, ou disciplinas "regionais", relacionadas aos aspectos comentados, à vez. É característica do conhecimento científico decompor para aprofundar o saber. Ele o tem feito, também quanto à arquitetura. Em alguns aspectos, o conhecimento tem maior tradição: vejam, por exemplo, a quantidade de títulos sobre os aspectos simbólicos ou estéticos nas bibliotecas de arquitetura, e os manuais que tratam de aspectos funcionais. Noutros aspectos, a tradição é menor, ainda que significativa, como nos topoceptivos, a constituírem linha de pesquisa aberta por Lynch (1999), mas com origem detectável, pelo menos, em Sitte (1992), embora este seja mais comumente classificado como esteta. Noutros, ainda, a tradição é quase nula, como nos aspectos afetivos, ${ }^{14}$ que merecem status independente mas são freqüentemente confundidos com outros, e.g. os simbólicos.

O paradigma epistemológico ainda hegemônico, ilustrado na discussão referida no início do texto, vem sendo superado (embora devagar). Nele, a arquitetura é estranha ao panteão das disciplinas científicas. Decorre que ela ressente-se de um complexo de inferioridade que a faz aceitar o status de adjetivo adicionado ao substantivo das disciplinas de maior tradição de pesquisa. Por isso nos incorporamos, alegres, a campos como "psicologia ambiental" ou "economia urbana" ou "estética arquitetônica", achando que assim subimos de patamar. Não. Esse foi o grande equívoco da "febre interdisciplinar" que atrasou perversamente o conhecimento da arquitetura. 
À mudança de postura metodológica devem corresponder mudanças taxonômicas. Quando o "espaço vem para a boca de cena", na bela expressão de Carlos Nelson Ferreira dos Santos (Turkienicz \& Malta, 1986), antigos rótulos não fazem jus à nova realidade. "Substantivar" as subdisciplinas da arquitetura significa propugnar por disciplinas cuja denominação, por exemplo, poderia ser a do Quadro 2.

Algumas expressões na coluna da direita do Quadro 2 são de uso mais corrente, outras menos. Mesmo quando corrente, o uso não diz respeito a uma disciplina regional, como propugnado aqui, mas a um tipo de manifestação empírica, a revelar a hegemonia do velho paradigma. Questionemos: por que a primeira idéia que nos vem à cabeça quando falamos em "sociologia urbana" é a de um corpo de conhecimento consolidado (uma disciplina, portanto), e não a idéia de manifestações empíricas de costumes urbanos? Por que, ao contrário, se encontramos a expressão "arquitetura bio-climática", a primeira idéia não $e ́$ a de um corpo disciplinar, mas a de uma arquitetura, digamos, "ecologicamente correta"? Por que a expressão "arquitetura funcional" nos remete a manifestações da arquitetura moderna, embora injusta ou mesmo equivocadamente? ${ }^{15}$ Trata-se do entendimento que o paradigma hegemônico impõe e que urge superar.

Quadro 2 - Aspectos e disciplinas "regionais" da arquitetura

\begin{tabular}{ll}
\hline ASPECTO & DISCIPLINA \\
\hline aspectos funcionais & arquitetura funcional \\
aspectos bio-climáticos & arquitetura bio-climática \\
aspectos econômicos & arquitetura econômica \\
aspectos sociológicos & arquitetura sociológica \\
aspectos topoceptivos, & arquitetura expressiva (para o conjunto, \\
afetivos, simbólicos, estéticos & ou então, especificamente, arquitetura \\
& topoceptiva, arquitetura afetiva, arquitetura \\
& simbólica, arquitetura estética) \\
\hline
\end{tabular}

No novo marco teórico, a questão da interdisciplinaridade se coloca de maneira diversa. Não se trata de um obscurantismo corporativo que menospreze o conhecimento de determinados campos disciplinares (e.g. sociologia urbana) em benefício de outros (e.g. arquitetura sociológica). Não há objeto empírico cuja compreensão prescinda do concurso de vários olhares. As relações das pessoas com o espaço urbano não são objeto privativo da arquitetura sociológica nem da sociologia urbana - são um campo comum a ambas. Contudo, os olhares de uma e outra disciplina diferem no ponto de partida, nos métodos, na ênfase e no rigor que conferem à descrição da realidade que procuram abordar. "Arquitetos sociológicos" têm por dever de ofício oferecer quadro preciso, exaustivo, profundo, do espaço produzido ou apropriado pelas pessoas; buscarão na sociologia urbana o aporte necessário à completude do quadro analítico, quanto aos atributos das pessoas envolvidas. Mas as categorias "importadas" não são quaisquer categorias, nem todas ajudam a entender melhor a arquitetura; não saber discriminá-las foi outro erro do "modo 2". Elas devem estar relacionadas às expectativas sociais em relação à forma-espaço dos lugares; têm de nos ajudar a entender a satisfação (ou não) das pessoas em relação ao desempenho arquitetônico. ${ }^{16}$ A sociologia urbana, por sua vez, não precisa, nem deve abordar com rigor a configuração da cidade, mas dirigir a ênfase às relaçóes entre as pessoas no âmbito urbano (classes sociais, gênero, gerações, etnias etc.). É para isto que ela está melhor preparada. Mutatis mutandis, buscarão na arquitetura so-
15 Como bem apontou Anderson, ao comentar que "função" é uma ficção em duplo sentido: uma mentira, pois a arquitetura funcional é uma impossibilidade, e uma narrativa, pois a "função" em arquitetura é sempre historicamente articulada a valores, idéias, costumes (Anderson, 1995).
16 A natureza multifacetada de nossas expectativas exige a importação de categorias de muitas disciplinas, a depender dos aspectos. Por exemplo, no âmbito dos aspectos sociológicos, importei de Giddens (1973) 0 conceito de classes sociais nas sociedades avançadas, para analisar 0 variado comportamento delas em relação ao espaço de Brasília (Holanda, 2002); para os aspectos funcionais, há que importar categorias da ergonomia; para os bio-climáticos, da biologia, da climatologia e da física; para os topoceptivos, da psicologia; etc. 
17 Hillier e Leaman abordaram o tema em artigos pioneiros nos anos 1970: Hillier \& Leaman, 1972, 1974, 1976.

18 Contudo, há muitos cientistas sociais que são "espacóólogos". É o caso de Durkheim (1964) com os conceitos de solidariedade mecânica e solidariedade orgânica, claramente espaciais, fundamentais para entendermos modos de vida não-urbanos e urbanos; de LéviStrauss (1977), em sua clássica análise da aldeia Bororo; de vários trabalhos de Michel Foucault, Erving Goffman, Pierre Bourdieu, Marc Augé, Michel de Certeau etc. Sua contribuição à arquitetura é inestimável.

19 Vejo com otimismo os excelentes trabalhos de Iniciação Científica produzidos por estudantes de graduação em arquitetura, a revelar grandes pesquisadores em potencial (migração do campo "1" para 0 "2"). Na pós-graduação em arquitetura a participação de estudantes oriundos de áreas aparentemente distantes (migracão do campo "3" para 0 "2") vem iluminar questões morfológicas. Por familiaridade, cito duas teses de doutorado em preparação: Franciney Carreiro de França (As características socio-morfológicas no Distrito Federal: morar em apartamentos) e Rômulo José da Costa Ribeiro (Análise da Configuração Urbana, por Meio de Índices de Qualidade de Vida e Qualidade Ambiental, em Apoio à Gestão de Cidades), são oriundos respectivamente da matemática e da geologia, e trazem para o campo da arquitetura avançados procedimentos quantitativos e de geo-processamento.

20 Como proposto por Robert Weaver (1968), apud ELLIN (1999, p. 65). A idéia chegou a desembocar na criação de cursos interdisciplinares de graduação para formar "generalistas". Isso é completamente diferente das experiências bem-sucedidas de trabalho em equipes interdisciplinares, como as realizadas pela SUDENE dos "tempos heróicos" (início dos anos 1960), ou da formação em nivel de pós-graduação como instrumento para aperfeicoar formas de diálogo interáreas no trato de problemas concretos, como nos CEMUAMs - Cursos de metodolo- ciológica o aporte necessário à completude do seu trabalho, segundo a mesma idéia: um aporte complementar, subsidiário. ${ }^{17}$

\section{MOdO 4: A "SEDUÇÃO" DE CIENTISTAS A-ESPACIAIS PARA O CAMPO MORFOLÓGICO}

As observaçōes anteriores referem-se ao necessário diálogo entre arquitetos e outras formaçōes, mantidas as respectivas identidades. Mas o desenvolvimento da arquitetura como disciplina vem ganhando muito também mediante mudanças nas tradicionais identidades acadêmico-profissionais. Vimos acima os ganhos decorrentes quando os arquitetos migram do campo "1" para o "2" (Quadro 1). Agora, levo a condenação do obscurantismo corporativista mais longe. Se a interação entre arquitetos (agora no campo "2") e cientistas sociais (no campo "3") já é profícua (comentada no modo anterior), mais ainda o será se houver uma migração inversa, agora dos cientistas do campo " 3 " para o campo "2". Isso também pressupóe mudança de identidade. Ao migrarem para o centro do diagrama, cientistas sociais transmutam-se em "morfólogos" - passam utilizar sua "caixa de ferramentas" teórico-metodológica para iluminar a configuração dos lugares, enriquecendo sobremaneira o conhecimento da realidade.

Portanto, sejam bem-vindos cientistas sociais ou da natureza ou das exatas, de todas as categorias para o campo disciplinar da arquitetura, sem que tenham de obter o respectivo diploma! Mas isso implica que se debrucem sobre os códigos arquitetônicos, passem a pensar morfologicamente, não a-espacialmente, como é mais de sua tradição. ${ }^{18} \mathrm{~A}$ dupla "migração" dos campos extremos para o campo central do Quadro 1 dá excelentes frutos. ${ }^{19}$ Faz de todos "pensadores reflexivos morfológicos", dá enorme impulso ao aprofundamento do campo disciplinar da arquitetura. Ao contrário, a negação do aprofundamento disciplinar e a defesa de "um novo tipo de generalista urbano", um "novo tipo de Homem Renascentista moderno", ${ }^{20}$ requenta posições falidas de quase 40 anos atrás.

Não importa o diploma do pesquisador ou a agremiação a que formalmente pertence, mas seu olhar sobre os lugares. A "senha" para entrar no campo "2" não é o rótulo contido no diploma, mas "morfologia". Dos três professores mais importantes na minha formação - Delfim Fernandes Amorim, Evaldo Coutinho e Bill Hillier - , apenas o primeiro é arquiteto. Amorim (1917-1972), português naturalizado brasileiro, teve forte influência na formação dos arquitetos da Faculdade de Arquitetura da Universidade Federal de Pernambuco ao longo de quase duas décadas, e foi um dos principais mentores e partícipes da Escola do Recife. ${ }^{21}$ O pernambucano Evaldo Coutinho (n. 1911) é exemplo emblemático: advogado por diploma, filósofo e arquiteto-esteta por opção, é autor do clássico O espaço da arquitetura (Coutinho, 1970), obra essencial no campo da filosofia da arte aplicada à arquitetura (ou no campo da arquitetura estética, nos nossos termos). O inglês Bill Hillier (n. 1937), bacharel em literatura, é fundador da Teoria da Sintaxe Espacial, influente linha de investigação que se difundiu por inúmeros países, inclusive no Brasil. ${ }^{22}$

As "disciplinas regionais" (ou subdisciplinas) da arquitetura vêm, sim, consolidando-se avan la lettre. Breves exemplos o ilustram: 1) manuais de variados tipos (Neufert \& Neufert, 2004, Prinz, 1980, entre outros) dizem respeito aos aspectos funcionais; 2) Romero (1988) investiga aspectos bio-climáticos ao examinar relações forma urbana $x$ conforto ambiental; 3) Mascaró (1985) pesquisa aspectos econômicos ao estudar relações configuração de cidades e edifícios $x$ seus custos de produção e manutenção; 4) trabalhos de Anderson (1978-EEUU), Mitchell (2000-EEUU), Castex et al. (1977-França), Santos \& Vogel (1985-Brasil), Hillier (1996-Inglaterra) e a maioria da pesquisa em "sintaxe espa- 
cial" estão no âmbito dos aspectos sociológicos - cada autor a enfocar, à sua maneira, relações modos de vida $x$ configuração urbana; 5) retomando e desenvolvendo a tradição de Lynch (1999), Kohlsdorf (1996) estuda os aspectos topoceptivos ao relacionar configuração urbana $x$ formação de imagens mentais; 6$)$ a dimensão simbólica do lugar é tema de Silva (1985), no Brasil, e dos fenomenólogos em geral, como Norberg-Schulz (1979) e Scully (1989); 7) embora a literatura raramente separe os aspectos afetivos dos simbólicos, os primeiros também são o foco de fenomenólogos, como Seamon (2000); 8) nos aspectos estéticos sobressai, no Brasil, o trabalho de Gorovitz (1985, 1993). Nada disto "combinei com os adversários", na espirituosa frase do Garrincha: o enquadramento dos autores na taxonomia é de minha responsabilidade, um exemplo de como o estado da arte pode ser caracterizado. Muitos possivelmente contestariam os respectivos rótulos e os conceitos propostos.

Os trabalhos são sintoma eloqüente de que a pesquisa sobre os aspectos da arquitetura é necessária e está sendo feita. Entretanto, a vertente "aspectual", em "profundidade", co-existe com outra, mais comum, em "extensão", igualmente legítima. Nesta, a pesquisa e a crítica preferem considerar a arquitetura globalmente, não em enfoques particulares. Preferem identificar como a confluência de vários aspectos proporciona identidade a um panorama da arquitetura delimitado no tempo ou no espaço. É a abordagem típica das disciplinas de história nas faculdades de arquitetura, e.g. "arquitetura barroca" (delimitação no tempo) ou "arquitetura brasileira" (delimitação no espaço). Na tradição, os aspectos comparecem (como não fazê-lo?!), contudo, de maneira global: quanto mais abrangente a abordagem, melhor. ${ }^{23} \mathrm{O}$ problema existe quando se vende uma parte pelo todo, quando uma opção por determinado aspecto é feita na análise, mas não explicitada - por exemplo, pelos aspectos estéticos, como é predominante na historiografia em arquitetura. É como se uma dimensão fosse a única a interessar, ou pelo menos a mais importante, em quaisquer casos. Não é assim. O desempenho da arquitetura pode ser contraditório entre aspectos - bom em uns, ruim em outros - e ela torna-se referência histórica quando suas qualidades fazem por merecê-lo, malgrado seus defeitos. Brasília, uma das mais importantes realizaçôes arquitetônicas ${ }^{24}$ de todos os tempos, já entrou para a história. Embora não se explicite assim, ela é legitimamente considerada Patrimônio Cultural da Humanidade pelos aspectos, e.g., bio-climáticos, topoceptivos, simbólicos e estéticos, apesar dos problemas sociológicos, funcionais e econômicos que tem (e.g. Holanda, 2002, 2003), alguns com origem no projeto, outros no desenvolvimento posterior da cidade. É no mínimo curioso como a crítica preconceituosa ou desinformada ou superficial de autores como Holston (1993), Rykwert (2000), Frampton, Tafuri, Zevi (Zein, 2001), passa ao largo de tais contradições e, principalmente, falha em reconhecer a importância histórica da cidade.

\section{ARQUITETURA COMO CIÊNCIA HUMANA}

Ciências humanas são ciências sobre práticas humanas. Como sintética e elegantemente formulou Nunes, ${ }^{25}$ a filosofia estuda relações entre seres humanos e idéias; a economia, relaçōes entre seres humanos e coisas; a sociologia, relações dos seres humanos entre si. Parafraseando Nunes, sugiro: a criação ou usufruto de lugares são práticas humanas e a disciplina da arquitetura como ciência humana estuda relaçôes entre os lugares e as pessoas, do ponto de vista dos aspectos funcionais, bio-climáticos, econômicos, sociológicos, topoceptivos, gia do urbanismo e administração municipal, realizados pelo IBAM - Instituto Brasileiro de Administração Municipal (o autor teve o privilégio de fazer 0 curso na edição 1971-72, sob a direção de Adina Mera e Marcos Mayerhofer).

21 "Pela qualidade e relativa homogeneidade da produção arquitetônica do período, muitos estudiosos sugerem a existência de uma escola de arquitetura - a Escola do Recife." (Amorim, 2003)

22 Bill Hillier escreveu com Julienne Hanson o livro que reuniu inicialmente os principais aspectos da teoria (Hillier \& Hanson, 1984). Publicou depois Hillier (1996). Simpósios internacionais bienais desde 1997 têm reunido pesquisadores de inúmeros países que utilizam a teoria. No Brasil, os pesquisadores concentram-se nas universidades: UFRN, UFPE, UnB, UFSC e URGS. Testemunhei 0 surgimento da teoria por ocasião da minha pós-graduação em Londres, nos anos 1970. Ela foi empregada na minha dissertação de mestrado e na minha tese de doutorado (esta publicada em Holanda, 2002), ambas realizadas sob a supervisão de Bill Hillier.

23 No Brasil, exemplo paradig mático da tradição é o trabalho pioneiro de Nestor Goulart Reis Filho. Quando pesquisar arquitetura era "coisa de intelectuais diletantes" e até motivo de escárnio nas faculdades de arquitetura, Reis Filho publicou o seminal Contribuição ao Estudo da Evolução Urbana no Brasil (1500-1720) (1968). Desde então tem contribuído ininterruptamente para a compreensão da arquitetura brasileira. Escreveu ou organizou 18 livros (http://buscatextual.cnpq. br/buscatextual/index.jsp, acesso em 03/04/2006). Há antecedentes quanto à reflexão sobre arquitetura no Brasil. Vale citar, pelo menos, os escritos de Lucio Costa a partir dos anos 1930 (vide Costa, 1995).

24 Lembro que uso "arquitetura" lato sensu, a englobar todas as escalas: edilícia, urbanística, paisagística.

25 Brasilmar Nunes, comunicação verbal na Sessão Coordenada referida no início do texto. 
afetivos, simbólicos e estéticos. As pessoas fazem-se humanas pelos modos de produção de bens materiais, pela língua que falam, pelos sistemas simbólicos que inventam, pelas maneiras de criar ou usufruir lugares. Mas o conjunto dessas "maneiras" é um campo ainda vasto. Prática humana é perceber estímulos visuais de uma seqüência de ruas e praças e a partir disso formar uma imagem mental estruturada (aspectos topoceptivos); é emocionar-se diante da leveza da arquitetura de Oscar Niemeyer (aspectos afetivos); é fazer a imagem do Cristo Redentor no Corcovado, Rio de Janeiro, representar a cidade inteira (aspectos simbólicos); etc. O conhecimento em todos esses campos é passível de se desenvolver no modo científico, e o tem feito, conforme exemplifiquei; todos são "humanidades". Entre os campos, tratarei de apenas um: a arquitetura sociológica.

A cada aspecto corresponde um campo de saber, uma subdisciplina da arquitetura. A cada subdisciplina correspondem categorias analíticas próprias, que conceituam a arquitetura e as expectativas sociais relativas aos aspectos. A arquitetura sociológica considera: 1) a realidade empírica lugar e 2) a realidade empirica expectativas sociais.

Para a disciplina arquitetura sociológica, a realidade empírica lugar é um sistema de barreiras e permeabilidades ao movimento, de transparências e opacidades à visão, de cheios e vazios, impregnados de práticas sociais. Cada lugar enquanto arquitetura implica uma peculiar organização dos elementos componentes: 1) superfícies, volumes, vãos, na escala dos edifícios; 2) edifícios, ruas, praças, áreas verdes, na escala dos assentamentos humanos de qualquer tipo - aldeias, vilas, cidades, metrópoles; 3) montanhas, vales, enseadas, praias, na paisagem natural. Lugares são ordenados em sistemas de contigüidades, continuidades, proximidades, separações, hierarquias, circunscrições. Dito mui sinteticamente, sistemas formal-espaciais variam, na história, no uso que fazem de barreiras/permeabilidades ou opacidades/transparências, em combinaçôes diversas. Interessam para a disciplina as relações entre tais sistemas e expectativas sociais específicas, como seguem.

Para a disciplina arquitetura sociológica, a realidade empirica expectativas sociais diz respeito a um sistema de encontros e esquivanças, de concentração e dispersão de pessoas. Cada sistema social implica uma peculiar maneira de organizar grupos de pessoas no espaço e no tempo, maneira que estabelece quem está próximo ou distante de quem, fazendo o quê, onde e quando. Sociedades variam, na história, em combinações diversas: as muito densas, que comprimem no espaço e no tempo toda classe de gente e práticas sociais diversas (todos estão próximos praticamente o tempo todo); as muito rarefeitas, que localizam diferentes tipos de pessoas e suas práticas em lugares especializados por categoria, lugares separados por grandes distâncias ou fortes barreiras físicas, pessoas cuja interação através do espaço é descontínua no tempo; combinações das duas coisas - e.g. concentrar separadamente - como é típico das sociedades contemporâneas com seus enclaves fortificados, campi universitários, centros cívico-administrativos, shopping centers, edge cities.

Vasta evidência empírica aponta para uma congruência histórica entre configurações formal-espaciais e sistemas sociais: as sociedades não são infinitamente maleáveis como para caber em qualquer camisa de força construída em pedra e cal e não se pode realizar impunemente qualquer absurdo arquitetônico. Todavia, muitas teorizaçóes em arquitetura estão longe de reconhecer a evidência. A dificuldade explica-se pelos equívocos cometidos pela ideologia do Movimento Moderno, que pretendia fazer brotar do lápis uma nova sociedade. ${ }^{26}$ Amadurecidos pelo fracasso das idéias, hoje o tema se nos coloca de maneira diferente: arquitetura e gente são coisas relacionadas, mas distintas. Falar em congruência não é falar em determinação bi-unívoca entre arquitetura e comportamento, mas 
é reconhecer que a arquitetura cria, sim, um campo de possibilidades e de restriçôes, possibilidades que podem (ou não) ser exploradas, restrições que podem (ou não) ser superadas. Exemplo de possibilidades que podem ser desprezadas: espaços públicos historicamente surgidos para comportar muita gente em forte interação cotidiana podem hoje estar desertos porque mudou o modo de vida das pessoas, embora habitem os antigos lugares (onde estão as cadeiras nas calçadas dos bairros tradicionais das cidades brasileiras?). Exemplo de restriçóes que podem ser superadas: no caso-limite da prisão, detentos podem cavar túneis e fugir. Os fatos não negam as possibilidades e restrições intrinsecas às configuraçóes arquitetônicas, mas revelam que as relaçóes de determinação entre arquitetura e comportamento são mais sutis do que um dia imaginamos. Nem ela determina nosso comportamento como se fôssemos desprovidos de vontade, iniciativa e capacidade de superar limites, nem ela é neutra, como foi a "solução" adotada por muitos teóricos. Tafuri e Rossi, por exemplo, passaram a ver a arquitetura como vazia de conteúdo, sobre a qual podemos colar os rótulos que quisermos: "a arquitetura por si própria não pode ser democrática ou fascista; somente as pessoas podem fazê-la uma coisa ou outra” (apud Ellin, 1999). Foram secundados por Léon Krier: "não existe arquitetura autoritária nem democrática. Existem somente meios autoritários e democráticos de produzir e usar a arquitetura. (...) A arquitetura não é política, apenas pode ser usada politicamente" (apud Ellin, 1999). Isso não agride apenas o bom senso, agride vasta evidência empírica. Sobre o tema determinismo arquitetônico, Tafuri, Rossi e Krier jogaram fora "a água suja do banho junto com o bebê". Compreender as relaçóes entre arquitetura e sociedade em um novo patamar de qualidade é o desafio da arquitetura sociológica.

Em suma, a arquitetura sociológica, como um campo de saber afeito às ciências humanas, preocupa-se em revelar as relaçóes entre arquitetura e sociedade, mais especificamente entre as configurações de edifícios, cidades e da paisagem natural entendida como arquitetura (ver conceituação acima) e as maneiras pelas quais as pessoas fazem o quê, como, onde, quando e com quem - as maneiras como se estruturam encontros interpessoais, de forma mais ou menos determinística, mais ou menos casual, concentrados ou não no espaço ou no tempo. Talvez a essencial contribuição paradigmática que a abordagem implica esteja expressa no axioma: há implicaçôes intrínsecas às configuraçôes arquitetônicas, traduzíveis em termos de possibilidades e limitações contidas nas próprias configuraçôes, que ainda têm sido precariamente entendidas pela literatura e pela pesquisa (e isso sem prejuízo do nosso livre arbítrio, aparentemente desprezado pelas máximas determinísticas do Movimento Moderno). A importância da reflexão está em que estas dimensões socioespaciais têm profundas implicações em relação a estruturações sociais, simetrias ou assimetrias sociais, enfim, estruturações de poder, como brevemente exemplificam os estudos relatados a seguir (ver também Holanda, 2002).

\section{ARQUITETURA SOCIOLÓGICA - EXEMPLOS}

A arquitetura sociológica - esse peculiar olhar sobre a forma-espaço da arquitetura tem motivado pesquisas e embasado projetos de urbanismo na FAU - Universidade de Brasília. Todavia, dado o espaço disponível, a prioridade foi pela exposição dos fundamentos teóricos da disciplina, não pelo exame pormenorizado de estudos de caso. A seguir ofereço indicaçôes sumárias sobre os estudos, cujo desenvolvimento está nas fontes indicadas. Os exemplos cobrem diversas escalas: 
1) Pesquisa sobre transformações do espaço doméstico ante o modo de vida contemporâneo, a implicar "casas dentro de casas", uma hiper-valorização da privacidade individual pela criação de pequenos mundos semi-autônomos nos quartos das residências (França, 2001). O estudo revela um "código de espaço doméstico de classe média”, comum à arquitetura erudita produzida por arquitetos, e à arquitetura banal, produzida, e.g., por desenhistas sob orientação direta dos moradores e assinada por profissionais formalmente habilitados para tal.

2) Projeto de revitalização da Av. W-3, Brasília, em que foram consideradas as mudanças morfológicas e de estilo de vida da metrópole brasiliense que provocaram a decadência da avenida, um dia o centro vital da cidade (Holanda, 2003). Discute-se a importância de incluir novos espaços domésticos em áreas atualmente estritamente comerciais e de serviços, e o contrário: a inclusão de serviços em quadras residenciais, medida que sacramenta tendência inelutável. Argumenta-se sobre as vantagens sociológicas de ambas e se demonstra como elas não ferem o estatuto do tombamento, contradizendo a visão estatal errada sobre o tema.

3) Estudo sobre a forma-espaço do Distrito Federal, a revelar os custos sociais da "excentricidade" da Capital: $82 \%$ dos empregos formais estão onde moram menos de $10 \%$ da população, numa área de relativa segregação física ante a metrópole como um todo (o Plano Piloto) (Holanda, 2003). Mostra-se como a metrópole Brasiliense é desequilibrada, quando examinadas as relações entre moradias, empregos e acessibilidade.

4) Projeto de uma superquadra em Brasília (SQN-109) realizado a partir da análise crítica da experiência pregressa (Holanda, 2003). Embora bio-climaticamente confortáveis e com paisagismo agradável, identificaram-se problemas funcionais, sociológicos e imagéticos nas superquadras existentes, problemas que se procurou evitar no projeto.

5) Projetos de expansão urbana realizados pelos estudantes de graduação para ocupar áreas centrais da metrópole até hoje vazias. Há áreas para novos bairros na Capital, mas cuja destinação, a manterem-se as diretrizes atuais, irão reforçar a conhecida segregação socioespacial da metrópole. Os projetos dos estudantes propõem tipos edilícios variados, cuja conseqüência seria uma maior democratização da cidade em termos de apropriação do espaço por distintas classes sociais. Embasa-se em pesquisa referida no item a seguir.

6) Pesquisa sobre as relações poder aquisitivo dos habitantes $x$ configuração formalespacial dos lugares onde moram (Holanda, 2006). Estudo em andamento mostra que a segregação socioespacial da Capital tem origem no projeto. A variedade limitada de tipos edilícios no Plano Piloto (inicialmente apenas edifícios de seis pavimentos sobre pilotis nas superquadras e "casas individuais" próximas à orla lacustre) resultou no surgimento precoce das cidades satélites para famílias de baixo poder aquisitivo. Sem guarida no Plano, os tipos "inadequados" implantaram-se a quilômetros de distância. A segregação socioespacial da Capital foi comandada por políticas públicas como resposta a princípios ideológicos, não como resultado de mercado, regra nas demais cidades brasileiras. Todavia, há permanência de faixas de renda baixa no coração da metrópole, principalmente na Vila Planalto, remanescente de antigo acampamento de empreiteiras, distante apenas de 1.500 metros da Praça dos Três Poderes, e nos blocos “JK", edifícios de três pavimentos, sem pilotis, menos palatáveis às classes médias e altas. A tese é: a arquitetura dos lugares está fortemente relacionada à permanência, mais de quarenta anos após a inauguração da cidade. Os achados, se explorados, teriam grande importância para políticas habitacionais mais democráticas. 


\section{CONCLUSÃO}

O texto apela ao conhecimento disciplinado, pois dissecar a realidade em suas múltiplas dimensões faculta ir mais longe no domínio e no aperfeiçoamento de nossas práticas.

O texto é otimista: identifica as frentes em que o conhecimento científico em arquitetura está sendo produzido. Todavia, como acontece nas demais ciências humanas (dizem que nas exatas também...), paradigmas conflitantes vão co-existir enquanto vivermos em sociedades com interesses contraditórios: elas produzem idéias à sua imagem e semelhança. Por um lado, Hillier, Mitchel e Anderson lançam novas luzes sobre velhos temas; por outro, produzem-se "manifestos" com cheiro de mofo: a Carta do Novo Urbanismo (Congress for the New Urbanism, 2001), a Nova Carta de Atenas (Conselho Europeu de Urbanistas, 2003), o livro A Vision of Britain, de Sua Alteza Real o Príncipe de Gales (The Prince of Wales, 1989). O último embasou o projeto retrô e a construção de Poundbury, a "nova" cidade "medieval" inglesa, em que participaram entusiasticamente Léon Krier e Andrés Duany, papas do "novo urbanismo". ${ }^{27}$

$\mathrm{O}$ apelo ao fortalecimento disciplinar o é também por uma abordagem interdisciplinar dos problemas, mas cujos participantes detenham posições sólidas para o confronto de idéias e o enfrentamento de questôes práticas. Não sugiro que nos fechemos em copas na disciplina da arquitetura. Pelo contrário, o texto é uma provocação, particularmente aos cientistas sociais: pensemos, juntos, as relações arquitetura $x$ sociedade, cada um com seu olhar. E, eventualmente, transformemo-nos, todos, em "morfólogos". Questionemos as respectivas categorias analíticas. $\mathrm{O}$ aprofundamento disciplinar implica a construção de "pontes" entre a disciplina da arquitetura e as ciências exatas, da natureza ou humanas; a arquitetura sociológica é um exemplo. As pontes permitem o diálogo e levam o conhecimento a novos patamares de qualidade, condição necessária, mas não suficiente para melhorar a realidade - "ah, se conhecer resolvesse tudo!"...

\section{B IBLIOGRAFIA}

AMORIM, L. "Arquitetura”. In ROSEMBERG, A. (Org.) Pernambuco: 5 Décadas de Arte. Recife: Quadro Publicidade e Design Ltda., 2003.

"A ficção da função". Anais do $4^{\circ}$ SEDUR - Seminário sobre desenho urbano no Brasil. Brasília: Faculdade de Arquitetura e Urbanismo, Universidade de Brasília, Secretaria de Desenvolvimento Urbano do Governo do Distrito Federal, 1995.

. (Ed.) On Streets. Cambridge: MIT Press, 1978.

CASTEX, J et al. Formes urbaines: de l'ilôt à la barre. Paris: Dunod, 1977.

Congress for the New Urbanism. Charter of New Urbanism. 2001 (http://www.cnu.org/ cnu_reports/Charter.pdf (acessado 24.11.2006))

COSTA, L. "Arquitetura", Biblioteca de Educação e Cultura, MEC/Fename, Bloch, n. 4, Rio de Janeiro, p. 7, 1980; Apud GOROVITZ, M. Brasilia, uma questão de escala. São Paulo: Projeto, 1985.

. Lúcio Costa: registro de uma vivência. Empresa das Artes, São Paulo, 1995. COUTINHO, E. O espaço da arquitetura. Recife: Universidade Federal de Pernambuco, 1970.

DURKHEIM, E. The Division of Labour in Society. New York: The Free Press, 1964.

ELLIN, N. Postmodern urbanism. New York: Princeton Architectural Press, 1999.
27 Poundbury foi construída em terras do Príncipe Charles. Ver excelente análise crítica em Willians, 2004.

Frederico de Holanda é professor associado da Faculdade de Arquitetura e Urbanismo, Universidade de Brasilia, PhD em arquitetura pela Universidade de Londres (1997).

E-mail: fredhol@unb.br.

Artigo recebido em maio de 2007 e aprovado para publicação em julho de 2007. 
FRANÇA, F. C. Meu quarto, meu mundo: configuração espacial e modo de vida em casas de Brasilia. Dissertação de Mestrado, Programa de Pesquisa e Pós-graduação em Arquitetura e Urbanismo, Faculdade de Arquitetura e Urbanismo, UnB. Brasília: s.n., 2001.

GIDDENS, A. The class structure of the advanced societies. London: Hutchinson of London, 1973.

GOROVITZ, M. Brasilia, uma questão de escala. São Paulo: Projeto, 1985.

. Os riscos do projeto - contribuição à análise do juizo estético na arquitetura.

São Paulo/Brasília: Edunb/Studio Nobel, 1993.

HILLIER, B. Space is the machine. Cambridge: Cambridge University Press, 1996.

HILLIER, B.; HANSON, J. The Social Logic of Space. Cambridge: Cambridge University Press, 1984.

HILLIER, B.; LEAMAN, A. "A new approach to architectural research". RIBAJ, Dec. 1972, p.517-21.

. "Architecture as a discipline". JAR 5/1, March 1976, p.28-32.

"How is design possible?". JAR 3/1, Jan. 1974, p.4-11.

HOLANDA, F. Afetos da arquitetura. Brasília: s.n., s.d.

"Brasília: ciudad moderna, ciudad eterna". In: VILLAESCUSA, E. R., FI-

GUEIRA, C. V. Brasilia 1956-2006 - de la fundación de una ciudad capital, al capital de la ciudad. Barcelona: Editorial Milenio, 2006, pp. 127-173.

(Org.) Arquitetura \& Urbanidade. São Paulo: ProEditores Associados Ltda,

2003.

HOLANDA, F. O espaço de exceção. Brasília: Editora Universidade de Brasília, 2002.

HOLANDA, F.; KOHLSDORF, G. "Sobre o Conceito de Arquitetura". Anais do Seminário Nacional - O Estudo da História na Formação do Arquiteto, FAUSP/FAPESP, 1995, p.196-203.

HOLSTON, J. A cidade modernista - Uma critica de Brasilia e sua utopia. São Paulo: Companhia das Letras, 1993.

KOHLSDORF, M. E. A Apreensão da Forma da Cidade. Brasília: Editora Universidade de Brasília, 1996.

KRUFT, H.-W. A history of architectural theory from Vitruvius to the present. New York: Princeton Architectural Press, 1994.

KUHN, T. S. Estrutura das revoluçôes cientificas. São Paulo: Perspectiva, 2003.

LÉVI-STRAUSS, C. Structural anthropology. Penguin Books, 1977.

LYNCH, K. A imagem da cidade. São Paulo: Martins Fontes, 1999.

MASCARÓ, J. L. O Custo das Decisóes Arquitetônicas. São Paulo: Nobel, 1985.

MITCHELL, W. J. E-topia. Cambridge: The MIT Press, 2000.

NEUFERT, E.; NEUFERT, P. Arte de projetar em arquitetura. Barcelona: Gustavo Gili, 2004.

NORBERG-SCHULZ, C. Genius Loci-Paesaggio, Ambiente, Architettura. Electa Editrice, Milano, 1979.

ORNSTEIN, S. Avaliação Pós-Ocupação do Ambiente Construido. São Paulo: Studio Nobel, 1997.

POPPER, K. Conjectures and refutations - the growth of scientific knowledge. London: Routledge and Kegan Paul, 1963.

PRINZ, D. Urbanismo I. Projecto Urbano. Lisboa: Editorial Presença, 1980.

REIS FILHO, N. G. Contribuição ao Estudo da Evolução Urbana no Brasil (1500-1720).

São Paulo: Livraria Pioneira Editora/Editora da Universidade de São Paulo, 1968. 


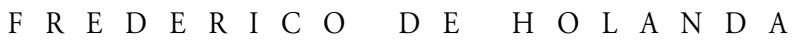

ROMERO, M. A. B. Princípios bio-climáticos para o desenho urbano. São Paulo: Projeto Editores, 1988.

RYKWERT, J. The seduction of place - The city in the twenty-first century. London: Weidenfeld \& Nicolson, 2000.

SANTOS, C. N. F.; VOGEL, A. Quando a rua vira casa - a apropriação de espaços de uso coletivo em um centro de bairro. São Paulo: Projeto Editores, 1985.

SCULLY, V. Pueblo / Mountain, Village, Dance. The University of Chicago Press, Chicago and London, 1989.

SEAMON, D. "Phenomenology, place, environment, and architecture: a review of the literature”. Environmental \& Architectural. Phenomenology Newsletter, 2000.

SILVA, E. Arquitetura e Semiologia. Porto Alegre: Ed. Sulina, 1985.

SITTE, C. A construção das cidades segundo seus princípios artísticos. Organização e apresentação de Carlos Roberto Monteiro de Andrade. Tradução de Ricardo Ferreira Henrique. São Paulo: Editora Ática, 1992.

TURKIENICZ, B.; MALTA, M. (Org.) Desenho urbano - Anais do II SEDUR, CNPq/ Finep/Pini, 1986.

ZEIN, R. V. O lugar da crítica - ensaios oportunos de arquitetura. Porto Alegre: Faculdades Integradas do Instituto Ritter dos Reis, 2001.

ZEVI, B. Saber ver la arquitectura - ensayo sobre la interpretación espacial de la arquitectura. Buenos Aires: Editorial Poseidon, 1951.

Conselho Europeu de Urbanistas. A Nova Carta de Atenas 2003. http://www.dgotdu.pt/atenas.html, acesso em 11/05/2004.

The Prince of Wales Prince Charles. A vision of Britain. London: Doubleday, 1989.

WILLIAMS, R. The anxious city - English urbanism in the late twentieth century. London \& New York: Routledge, 2004.

A B S T R A C T Architecture is more common considered a craft, an art, a technique. The text considers as well a science which approaches places under a specific point of view, which is not akin to the one of other disciplines. I examine modalities of knowledge and I suggest that there has been a paradigmatic change in the field in the last decades. The change rescues reflexive-theoretical knowledge. To assert architecture as a scientific discipline does not deny, on the contrary, it strengthens interdisciplinarity in dealing with questions related to places produced or appropriated by people: I emphasise contributions of authors coming from other disciplinary fields, who look at places from the morphological point of view. I explore architecture as an independent variable: once ready, it affects people in various ways, among them the sociological way. The latte way may be summarized by mean of the following questions: does formal-spatial configuration (voids, solids, their relationships) imply desirable ways of individuals and groups (social classes, genders, generations etc.) localize themselves in places and move along them, and consequently desirable conditions for interpersonal encounters and avoidances and for the visibility of other? The type, quantity and relative localization of activities imply desirable patterns of utilization of places, in space and time?

K E Y W O R D S Relationships architecture/society; architecture as human science; sociological architecture. 